\title{
The Differences of Urinary Neutrophil Gelatinase-Associated Lipocalin (NGAL) Levels between Asphyxiated and Non-Asphyxiated Neonates
}

\author{
Nur Dian Firmani*, Tetty Yuniati, Dedi Rachmadi \\ Department of Child Health, Faculty of Medicine, Universitas Padjadjaran, Bandung, Indonesia \\ Email: ${ }^{*}$ nurdian.firmani@gmail.com
}

Received 22 June 2015; accepted 18 August 2015; published 21 August 2015

Copyright (C) 2015 by authors and Scientific Research Publishing Inc.

This work is licensed under the Creative Commons Attribution International License (CC BY). http://creativecommons.org/licenses/by/4.0/

(c) (i) Open Access

\begin{abstract}
Objective: To evaluate the differences of urinary NGAL levels between asphyxiated and non-asphyxiated neonates. Methods: This was a cross-sectional observational analytic study, including 34 newborns in Dr. Hasan Sadikin Hospital, Bandung, Indonesia. Sample collection was conducted from December 2014 to March 2015. Urine NGAL levels were evaluated using enzyme-linked immunosorbent assays (ELISA) technique. To determine the differences of urinary NGAL levels between asphyxiated and non-asphyxiated group we used Mann-Whitney $U$ test, and to determine the differences of gestational age and birth weight between these two groups we used Fisher's exact test. Results: Twenty males $(60 \%)$ and 14 females $(40 \%)$ neonates participated in the study. From 34 subjects, 17 neonates were diagnosed with asphyxia and 17 neonates without asphyxia. The results showed that urine NGAL levels had significantly increased in asphyxiated neonates. The median urine NGAL level in asphyxiated group is $95 \%$ CI: $506.7(60.0-651.7) \mathrm{ng} / \mathrm{mL}$, while the median urine NGAL level in non-asphyxiated group is $95 \%$ CI: $6.7(0.1-53.0) \mathrm{ng} / \mathrm{mL}$. Statistically, there were significant urine NGAL levels differences between asphyxiated and non-asphyxiated neonates $(p<0.001)$. There were no differences in gestational age and birth weight between asphyxiated and non-asphyxiated neonates $(p>0.05)$. Conclusions: Urinary NGAL levels in asphyxiated neonates were significantly higher than those in non-asphyxiated neonates. There were significant differences of urine NGAL levels between the groups.
\end{abstract}

\section{Keywords}

Neutrophil Gelatinase-Associated Lipocalin, Asphyxia, Neonates

\footnotetext{
${ }^{*}$ Corresponding author.
} 


\section{Introduction}

Neonatal asphyxia is still the leading cause of high morbidity and mortality in developed countries, as well as in developing countries including Indonesia. Global estimates for asphyxia-related neonatal deaths vary from 0.7 to 1.2 million, and about $99 \%$ of neonatal deaths are due to asphyxia occurred in low- and middle-income countries [1]. Incidence of neonatal asphyxia in Indonesia is about 3\% - 5\% of all live births [2].

Asphyxia could reduce renal blood flow and might cause organ dysfunction and tubular renal damage [3]-[6]. Damaged tubular cells will produce and secrete biological substances that related to innate immune response and inflammation process including protein [7]-[9]. Neutrophil gelatinase-associated lipocalin (NGAL) is a protein that is secreted by immune cells, hepatocytes, and renal tubular cells. Neutrophil gelatinase-associated lipocalin could be overly expressed after renal ischemic and it could be detected with higher concentration in urine [10][13].

Neutrophil gelatinase-associated lipocalin has been used as a biomarker for acute kidney injury (AKI) in critically ill neonates and children. From previous studies, Askenazi et al. [14] described urine NGAL levels in very low birth weight newborns which were diagnosed with AKI, and showed elevated urine NGAL levels. Krawczeski et al. [15] compared serum and urine NGAL levels in neonates and children after cardiopulmonary bypass (CPB), and showed elevated serum and urine NGAL levels 2 hours after CPB and it can be used for biomarker of AKI. Sarafidis et al. [16] compared serum and urine cystatin-c levels, serum and urine NGAL levels, and urine kidney injury molecule-1 (KIM-1) levels with serum creatinin levels in term asphyxiated and non-asphyxiated newborn, and showed a significant elevated serum cystatin-c levels, also elevated serum and urine NGAL levels in asphyxiated newborn. Serum and urine NGAL levels elevated in asphyxiated newborn with AKI inspite of non-AKI asphyxiated newborn [14]-[16].

The aim of this study is to evaluate the differences between urinary NGAL levels in asphyxiated neonates and non-asphyxiated neonates.

\section{Materials and Methods}

This cross-sectional study was performed in Neonatology Division of Dr. Hasan Sadikin Hospital Bandung, Indonesia from December 2014 to March 2015. Subjects of this study were calculated by unpaired data analysis for two independent groups, and minimum sample size estimation was 17 each group. Seventeen neonates were diagnosed as asphyxia based on 2 from the following American Academy of Pediatrics' criteria [17]: 1) umbilical cord arterial $\mathrm{pH}$ less than 7; 2) Apgar score of 0 to 3 for longer than 5 minutes; 3) neurologic manifestations (eg, seizures, coma, hypotonia); and 4) multisystemic organ dysfunction, and 17 neonates were born without asphyxia. The exclusion criteria were baby born with multiple congenital anomaly and mother with infection risks. This study was approved by the ethical committee of the Faculty of Medicine, Universitas Padjadjaran/Dr. Hasan Sadikin General Hospital Bandung, Indonesia.

Urine samples were collected after informed consent from their parents. Urine NGAL examination was performed with ELISA technique. Data were presented as mean, standard deviation, and median with range. Statistical parameters were calculated using SPSS $^{\mathrm{TM}}$ version 20.0. Due to unnormally distributed data, the nonparametric Mann-Whitney U test was used to determine the differences of urinary NGAL levels between the groups. The Fisher's exact test was used to determine the differences of gestational age and birth weight in both groups. p values $<0.05$ were considered as significant.

\section{Results}

Thirty four babies, who were born in Neonatology Division of Dr. Hasan Sadikin General Hospital in Bandung, Indonesia, consisted of 20 males and 14 females were divided into 17 asphyxiated neonates group and 17 nonasphyxiated neonates group. The clinical characteristics of the subjects are presented in Table 1, while factors which associated with urine NGAL levels are presented in Table 2.

The results from data analysis with Fisher exact test on the differences of gestational age and birth weight between asphyxiated and non-asphyxiated neonates were not significant (Table 2). The differences of urine NGAL levels between asphyxiated and non-asphyxiated neonates were analyzed using Mann-Whitney $U$ test, and they are presented in Table 3.

The median urine NGAL levels in both groups were statistically significant different $(\mathrm{p}<0.001)$. 
Table 1. Characteristics of the subjects $(n=34)$.

\begin{tabular}{|c|c|c|}
\hline Characteristics & Asphyxiated neonates $(n=17)$ & Non-asphyxiated neonates $(n=17)$ \\
\hline \multicolumn{3}{|l|}{ Gestational age, $\mathrm{n}$} \\
\hline$\leq 36$ weeks & 9 & 5 \\
\hline$>36$ weeks & 8 & 12 \\
\hline Birth weight (gram), mean (SD) & $2190(756)$ & $2727(760)$ \\
\hline \multicolumn{3}{|l|}{ Gender, n } \\
\hline Male & 10 & 10 \\
\hline Female & 7 & 7 \\
\hline \multicolumn{3}{|l|}{ Type of delivery, $\mathrm{n}$} \\
\hline Vaginal delivery & 8 & 6 \\
\hline Caesarian section & 8 & 10 \\
\hline Vacuum extraction & 1 & 1 \\
\hline \multicolumn{3}{|l|}{ Seizure, $\mathrm{n}$} \\
\hline Yes & 3 & 0 \\
\hline No & 14 & 17 \\
\hline
\end{tabular}

SD: standard deviation.

Table 2. Factors associated with urine NGAL levels.

\begin{tabular}{cccc}
\hline Variables & Asphyxiated neonates $(\mathbf{n}=\mathbf{1 7})$ & Non-asphyxiated neonates $(\mathbf{n}=\mathbf{1 7})$ & $\mathbf{p}$ Value \\
\hline $\begin{array}{c}\text { Gestational age, } n \\
\leq 6 \text { weeks }\end{array}$ & 9 & 5 & $0.163^{*}$ \\
$>36$ weeks & 8 & 12 & $1.0^{*}$ \\
Birth weight, $n$ & & & \\
$\leq 1500$ gram & 2 & 1 & 16 \\
$>1500$ gram & 15 & & \\
\hline
\end{tabular}

*Fisher's exact test.

Table 3. Urinary NGAL levels.

\begin{tabular}{cccc}
\hline Urine NGAL levels $(\mathbf{n g} / \mathbf{m L})$ & Asphyxiated neonates $(\mathbf{n}=\mathbf{1 7})$ & Non-asphyxiated neonates $(\mathbf{n}=\mathbf{1 7})$ & $\mathbf{p}$ Value \\
\hline Median & 506.7 & $0.7-53.0$ & $<0.001^{\dagger}$ \\
Range & $60.0-651.7$ & 0.1 \\
\hline
\end{tabular}

${ }^{\dagger}$ Mann-Whitney U test.

\section{Discussion}

Asphyxiated group had gestational age $\leq 36$ weeks more than $>36$ weeks while the mean gestational age was 34 (26 - 40) weeks, and the mean birth weight was 2190 (800 - 3400) gram. Non-asphyxiated group had gestational age $>36$ weeks more than $\leq 36$ weeks while the mean gestational age was $37(32-42)$ weeks, and the mean birth weight was 2727 (1500 - 3920) gram. This study is different from previous studies. Sarafidis et al. [16] and ElSalam et al. [18] included term neonates and excluded preterm and very low birth weight neonates.

This study also determined the differences of gestational age and birth weight as factors which were associated with urine NGAL levels between asphyxiated and non-asphyxiated neonates. There were no significant differences in gestational age and birth weight between the groups $(p=0.163 ; p=1.0)$.

The results of this study showed the median urinary NGAL levels in asphyxiated group was 506.7 (60.0 651.7) ng/mL, elevated significantly from normal value. The median urinary NGAL levels in non-asphyxiated group was 6.7 (0.1 - 53.0) ng/mL. Statistically, there were significant differences of urinary NGAL levels be- 
tween asphyxiated and non-asphyxiated group $(\mathrm{p}<0.001)$.

Neonatal asphyxia is a leading cause of renal hypoxia and ischemia. Reduced renal blood flow is a major cause of overly NGAL express in tubular renal [12]. Normally, circulating NGAL is filtered in the glomerulus and reabsorbed by the proximal tubule. Consequently, low levels of NGAL are detected in plasma and urine [12]-[14]. In renal tubular damage, circulating NGAL were not well reabsorbed by proximal tubule and induced synthesis NGAL de novo in distal tubule [11] [19]. Neutrophil gelatinase-associated lipocalin could elevate and could be detected in the higher concentration of urine before progressive renal damage and death cells [12] [20].

Previous studies with different subject had been conducted beforehand. Sarafidis et al. [16] compared urine NGAL levels between asphyxiated and non-asphyxiated term neonates, and showed that there were significant differences of urinary NGAL levels in both groups $(p=0.006)$, and urinary NGAL levels showed elevated in asphyxiated neonates with AKI inspite of non-AKI asphyxiated neonates. El-Salam et al. [18] reported urinary NGAL levels in term asphyxiated neonates had a significant elevation in 48 hours after birth and before the rising of creatinin serum levels than in control group $(p=0.01)$.

Limitation of this study is asphyxia based on AAP's criteria not to evaluate all of the criteria, but only from the Apgar score and $\mathrm{pH}$ in arterial blood gas because we required more time to observe other criteria. We also did not exclude multiple congenital anomaly condition from objective examination, but only from physical examination. NGAL examination was only to evaluate differences in asphyxiated and non-asphyxiated neonates, not including creatinin serum examination and not to observe occurrence of AKI. However, due to our limitations, more studies are required.

\section{Conclusion}

Urinary NGAL levels in asphyxiated neonates were significantly higher than those in non-asphyxiated neonates. There were significant differences of urine NGAL levels between the groups.

\section{Acknowledgements}

Our study was conducted with private funding. We thanked Professor Abdurachman Sukadi and Professor Herry Garna for initial manuscript preparation counseling. NDF, TY, and DR contributed to conception and design of the study, acquisition of data, interpretation and analysis of data, revising the article and final approval of the version submitted. We also thank to the parents for their children's participation in the present study.

\section{References}

[1] Lawn, J., Shibuya, K. and Stein, C. (2005) No Cry at Birth: Global Estimates of Intrapartum Stillbirths and Intrapartum-Related Neonatal Deaths. World Health Organization, Geneva, 83, 409-417.

[2] Alisjahbana, A., Hidayat, S., Mintardaningsih, Primadi, A., Harliany, E., Sofiatin, Y., et al. (1999) Management of Birth Asphyxia at Home and Health Center. Paediatrica Indonesiana, 39, 88-101.

[3] Askenazi, D.J., Ambalavanan, N. and Goldstein, S.L. (2009) Acute Kidney Injury in Critically Ill Newborns: What Do We Know? What Do We Need to Learn? Pediatric Nephrology, 24, 265-274. http://dx.doi.org/10.1007/s00467-008-1060-2

[4] Aggarwal, A., Kumar, P., Chowdary, G., Majumdar, S. and Narang, A. (2005) Evaluation of Renal Function in Asphyxiated Newborns. Journal of Tropical Pediatrics, 51, 295-299. http://dx.doi.org/10.1093/tropej/fmi017

[5] Andreoli, S.P. (2004) Acute Renal Failure in the Newborn. Seminars in Perinatology, 8, 112-123. http://dx.doi.org/10.1053/j.semperi.2003.11.003

[6] Agras, P.I., Tarcan, A., Baskin, E., Cengiz, N., Gurakan, B. and Saatci, U. (2004) Acute Renal Failure in the Neonatal Period. Renal Failure Journal, 26, 305-309. http://dx.doi.org/10.1081/JDI-200026749

[7] Theocharis, P.G.V., Tsampoura, Z., Basioti, M. and Andronikou, S. (2011) Renal Glomerular and Tubular Function in Neonates with Perinatal Problems. The Journal of Maternal-Fetal \& Neonatal Medicine, 24, 142-147. http://dx.doi.org/10.3109/14767058.2010.482602

[8] Durkan, A.M. and Alexander, R.T. (2011) Acute Kidney Injury Post Neonatal Asphyxia. The Journal of Pediatrics, 158, e29-e33. http://dx.doi.org/10.1016/j.jpeds.2010.11.010

[9] Jetton, J.G. and Askenazi, D.J. (2012) Update on Acute Kidney Injury in Neonate. Current Opinion in Pediatrics, 24, 1-6. http://dx.doi.org/10.1097/MOP.0b013e32834f62d5 
[10] Liborio, A.B., Branco, K.M. and Bezerra, C.T. (2014) Acute Kidney Injury in Neonates: From Urine Output to New Biomarkers. BioMed Research International, 2014, 1-8. http://dx.doi.org/10.1155/2014/601568

[11] Schmidt-Ott, K.M., Mori, K., Li, J.Y. and Kalandadze, A. (2007) Dual Action of Neutrophil Gelatinase-Associated Lipocalin. Journal of the American Society of Nephrology, 18, 407-413. http://dx.doi.org/10.1681/asn.2006080882

[12] Clerico, A., Galli, C., Fortunato, A. and Ronco, C. (2012) Neutrophil Gelatinase-Associated Lipocalin (NGAL) as Biomarker of Acute Kidney Injury: A Review of the Laboratory Characteristics and Clinical Evidences. Clinical Chemistry and Laboratory Medicine, 50, 1505-1517. http://dx.doi.org/10.1515/cclm-2011-0814

[13] Schmidt-Ott, K.M., Mori, K., Kalandadze, A., Liand, J.Y., Paragas, N., Nicholas, T., et al. (2006) Neutrophil Gelatinase-Associated Lipocalin-Mediated Iron Traffic in Kidney Epithelia. Current Opinion in Nephrology and Hypertension, 15, 442-449. http://dx.doi.org/10.1097/01.mnh.0000232886.81142.58

[14] Askenazi, D.J., Montesanti, A., Hunley, H., Koralkar, R., Pawar, P., Shuaib, F., et al. (2011) Urine Biomarkers Predict Acute Kidney Injury and Mortality in Very Low Birth Weight Infants. The Journal of Pediatrics, 159, 907-912. http://dx.doi.org/10.1016/j.jpeds.2011.05.045

[15] Krawczeski, C.D., Woo, J.G., Wang, Y., Bennett, M.R., Ma, Q. and Devarajan, P. (2011) Neutrophil GelatinaseAssociated Lipocalin Concentrations Predict Development of Acute Kidney Injury in Neonates and Children after Cardiopulmonary Bypass. The Journal of Pediatrics, 158, 1009-1015. http://dx.doi.org/10.1016/j.jpeds.2010.12.057

[16] Sarafidis, K., Tsepkentzi, E., Agakidou, E., Diamanti, E., Taparkou, A., Soubasi, V., et al. (2012) Serum and Urine Acute Kidney Injury Biomarkers in Asphyxiated Neonates. Pediatric Nephrology, 27, 1575-1582. http://dx.doi.org/10.1007/s00467-012-2162-4

[17] American Academy of Pediatrics and American College of Obstetricians and Gynecologists (2002) Care of the Neonate. In: Gilstrap, L.C. and Oh, W., Eds., Guidelines for Perinatal Care, 5th Edition, American Academy of Pediatrics, Elk Grove Village, 196-197.

[18] El-Salam, M.A., Zaher, M.M., Mohamed, R.A.E., Al Shall, L.Y., Saleh, R.A.M. and Hegazy, A.A. (2014) Comparison of Some Urinary Biomarkers of Acute Kidney Injury in Term Newborn with and without Asphyxia. Clinical Medicine and Diagnostics, 4, 23-28.

[19] Hooman, N., Nakhali, S. and Sharif, M.R. (2014) Update on Acute Kidney Injury in Pediatrics. Journal of Pediatric Nephrology, 2, 56-62.

[20] Myjak, B.L. (2010) Serum and Urinary Biomarkers of Acute Kidney Injury. Blood Purification, 29, 357-365. http://dx.doi.org/10.1159/000309421 